East African Medical Journal Vol. 85 No. 3 March 2008

ORAL HEALTH STATUS OF HANDICAPPED PRIMARY SCHOOL PUPILS IN DAR ES SALAAM, TANZANIA

E. N. M. Simon, DDS, PhD, Department of Oral Surgery and Oral Pathology, School of Dentistry, M. I. Matee, DDS, MSc, $\mathrm{PhD}$, Department of Microbiology and Immunology, School of Medicine, Muhimbili University of Health and Allied Sciences, P. O. Box 65014, Dar es Salaam, Tanzania and F. Scheutz, DDS, PhD, Department of Community Oral Health and Paediatric Dentistry, Dental School, Faculty of Health Sciences, Aarhus, Denmark

Request for reprints to: Dr. E. N. M. Simon, Department of Oral Surgery and Oral Pathology, School of Dentistry, Muhimbili University of Health and Allied Sciences, P. O. Box 65014, Dar es Salaam, Tanzania

\title{
ORAL HEALTH STATUS OF HANDICAPPED PRIMARY SCHOOL PUPILS IN DAR ES SALAAM, TANZANIA
}

\author{
E. N. M. SIMON, M. I. MATEE and F. SCHEUTZ
}

\begin{abstract}
Background: There is hardly any information regarding oral health status of handicapped primary school pupils in Tanzania. Determination of their oral health status could help in planning sustainable intervention programmes for this disadvantaged group.

Objectives: To determine caries and periodontal status and treatment needs of handicapped primary school pupils in Dar es Salaam, Tanzania.

Design: A descriptive cross-sectional study.

Setting: Uhuru Mchanganyiko and Buguruni special schools, Dar es Salaam.

Results: The sample consisted of $179(55.8 \%)$ males and $142(44.2 \%)$ females aged between 7 and 22 years. Majority $(71 \%)$ were deaf followed by blind $(17.8 \%)$ and mentally retarded $(8.7 \%)$. Six $(1.9 \%)$ pupils were both deaf and blind, while one $(0.3 \%)$ pupil was blind and mentally retarded. Forty one $(\mathbf{1 2 . 8 \%})$ pupils had at least one decayed deciduous tooth, with the mean (dmfs) ranging from 0.25 to 3.24. The deaf had the highest mean decayed surfaces, followed by the mentally retarded and the blind. There was only one $(0.3 \%)$ pupil who had a filled deciduous tooth. Thirty three $(10.3 \%)$ pupils had decayed permanent teeth and $31(9.7 \%)$ had missing permanent teeth. None of the decayed permanent teeth were restored. The blind had the lowest mean deciduous surfaces (DS) scores of between 0 and 1.0. In the mentally retarded group the mean DS ranged from 0.25 to 1.75 . About $73.5 \%$ of the studied group had bleeding of the gums, with the blind having the highest mean bleeding index scores $(\mathrm{p}<0.001)$ and about $82.8 \%$ of the pupils had calculus, with highest mean scores mainly among the blind $(\mathrm{p}=0.008)$.

Conclusion: The caries prevalence among handicapped primary school pupils was quite low. However, there was relatively high level of gingival bleeding and calculus. Regarding treatment needs, $23 \%$ required dental fillings mainly of one and two surface restorations and $82 \%$ required scaling and polishing. Despite these treatment needs these pupils had not received any dental attention.
\end{abstract}

\section{INTRODUCTION}

In Tanzania there is no study on oral health status among handicapped children. Studies conducted elsewhere on handicapped children have shown varying results; some showing poor oral health and others showing similar oral health status as those of normal children (1-5). These differences may be attributable, at least in part, to the differences in the level of disability and the level of oral health care given to the handicapped children. Further, the different groups of handicapped children differ greatly not only in their understanding capabilities but also in performing tasks. It is thus important to determine, for each of these groups, specific oral health status and treatment needs as well as appropriate preventive programmes.

In many countries, the frequency of attendance to health facilities is poorer for handicapped children $(6,7)$. This is especially so in developing countries, where being handicapped is even more stigmatising and poses greater barriers to all sorts of social services. Furthermore, many developing countries lack specific oral health programmes for handicapped children such as the specific plaque control programmes seen in the developed western countries (8). Thus, it is logical to assume that the oral health status of handicapped children is different from that of their counterparts in developed countries. The disabilities seen in handicapped children range from blindness, 
deafness, to mental retardation and cerebral palsy, with some children having more than one disability.

The aim of this study was to determine dental caries and periodontal disease status of primary school handicapped pupils with deafness, blindness and mental retardation in Dar-es Salaam, Tanzania.

\section{MATERIALS AND METHODS}

All handicapped pupils, who during the study period (July to August 2003), were attending Uhuru Mchanganyiko, and Buguruni special schools in Dar es Salaam were eligible for the study. These two primary schools were randomly selected from the four primary schools for the handicapped in Dar es Salaam. In Tanzania, the school system for the disabled differs from the normal system. The schoolentrance age for the disabled is not specific and ranges from seven years (which is the normal age for joining primary education) to twelve years depending on several factors, that is, pupil'sdisability, parent'sawareness and the willingness to take their children to school. Deaf pupils spend the first two years in grade 1 , one year in grade 2 , two years in grade 3 , one year in grade 4 , two years in grade 5 and one year each for grades 6 and 7. During the first and second grades, the blind are taught separately, concentrating mainly on their special language and join the other pupils after the second grade. School system for the mentally retarded is different from the other two categories because these pupils have to start grade one in a special class at different ages depending on the degree of their disability. Finally school enrolment for the mentally retarded children depends on reaching acceptable levels in pre-school centres.

Only pupils whose parents/guardians gave consent and with known birth dates and for whom oral examination was feasible were enrolled. We could not examine one of the eligible pupils due to lack of cooperation, bringing the overall participation rate to $99.7 \%$.

The following information was obtained from a combination of sources namely school records, teachers and the pupils: date of examination, date of birth, gender, and type of disability.

Dental caries examination: All dental examinations, including calibration for determination of reliability, were carried out by three examiners under natural daylight with the subject seated on an office chair. For diagnosis of dental caries we used WHO criteria (9) and dental status was scored as DMFS and DMFS for the primary and the permanent teeth, respectively.

Periodontal status: Periodontal status was assessed by determining; presence or absence of gingival bleeding and presence or absence of supra or sub-gingival calculus using a periodontal probe as recommended by the WHO (9) and followed by calculating the mean gingival bleeding and calculus indices.
Inter and intra examiner reliability: For both inter- and intra-examiner reliability each examiner randomly and blindly re-examined between thirty and thirty three patients, which is $10 \%$ of the studied population.

Ethical issues: This study involved oral examination only and was therefore not invasive and not painful. Participants wereenrolled after obtaining aninformed verbal consent from the parents or guardians. Participation in this study was purely voluntary and was aimed at improving the oral health status of this disadvantaged group of pupils. Pupils who were found to have oral health problems were given appropriate advice and/or were referred to appropriate dental health facilities. Ethical clearance was granted by the Muhimbili University of Health and Allied Sciences (MUHAS) research and publications committee and permission to conduct the study was granted by both the Dar es Salaam City Council and the City Medical Officer.

Data handling and statistical analyses: Data were keyed in twice on EpiData (10) and validated using EpiData's validation programme. Stata (11) was also used for descriptive and analytical purposes. The kappa coefficient statistic was used as measure of reliabilityof inter-and intra-examiner agreement using MedCalc (12) and Stata (11). A two-sided $\alpha$-level $=0.05$ was used, and its complement, $1-\alpha$, for the computation of $95 \%$ confidence intervals. Results were considered to be statistically significant if the corresponding P value was less than 0.05 .

\section{RESULTS}

There were $179(55.8 \%)$ males and $142(44.2 \%)$ females, a male-female ratio of 1.3:1 with an age range of between seven and 22 years (Table 1). The majority (71\%) of the examined pupils were deaf, followed by the blind $(17.8 \%)$ and mentally retarded $(8.7 \%)$ (Table 1). Six pupils (1.9\%) were both deaf and blind, while one child $(0.3 \%)$ was blind and mentally retarded.

Forty one pupils $(12.8 \%)$ had at least one decayed deciduous tooth, with the mean decayed deciduous teeth ranging from 0.25 to 3.24 (Table 2). Most of the decayed teeth were in the seven to nine years age group, with the deaf having the highest mean decayed surfaces, followed by the mentally retarded and the blind. There was only one $(0.3 \%)$ pupil who had a filled deciduous tooth. Thirty three $(10.3 \%)$ of the subjects had at least one decayed permanent tooth and $31(9.7 \%)$ had at least one missing tooth (Table 3 ). None of the subjects had any filled permanent tooth. The highest DS score was seen in the 17 - 22 year age group of the deaf with a mean DS score of 1.75. The blind had the lowest mean score of between 0 and 1.0. In the mentally retarded group the mean DS score ranged from 0.25 to 1.75 . 
Table 1

Distribution of the studied group according to main type of handicap and age group

\begin{tabular}{|c|c|c|c|c|c|c|c|}
\hline \multirow{2}{*}{$\begin{array}{l}\text { Age } \\
\text { group (years) }\end{array}$} & $\begin{array}{l}\text { Blind } \\
\text { No. }(\%)\end{array}$ & \multicolumn{2}{|c|}{$\begin{array}{c}\text { Deaf } \\
\text { No. } \quad(\%)\end{array}$} & \multicolumn{2}{|c|}{$\begin{array}{l}\text { Retarded } \\
\text { No. }(\%)\end{array}$} & \multicolumn{2}{|c|}{$\begin{array}{c}\text { Total } \\
\text { No. }(\%)\end{array}$} \\
\hline & $\begin{array}{ll}6 & 9.4\end{array}$ & 25 & 10.9 & 8 & 28.6 & 39 & 12.1 \\
\hline $10-12$ & 2132.8 & 51 & 22.3 & 16 & 57.1 & 88 & 27.4 \\
\hline $13-14$ & $14 \quad 21.9$ & 56 & 24.5 & 4 & 14.3 & 74 & 23.1 \\
\hline $15-16$ & $13 \quad 20.3$ & 61 & 26.6 & 0 & 0.0 & 74 & 23.1 \\
\hline $17-22$ & 1015.6 & 36 & 15.7 & 0 & 0.0 & 46 & 14.3 \\
\hline Total & 64100 & 229 & 100 & 28 & 100 & 321 & 100 \\
\hline
\end{tabular}

Table 2

Mean number of decayed surfaces in the decidous dentition according to handicap and age group

\begin{tabular}{lccccccccc}
\hline $\begin{array}{l}\text { Age } \\
\text { (years) }\end{array}$ & No. & $\begin{array}{c}\text { Blind } \\
\text { Mean }\end{array}$ & Min-Max & No. & $\begin{array}{c}\text { Deaf } \\
\text { Mean }\end{array}$ & Min-Max & No. & $\begin{array}{c}\text { Retarded } \\
\text { Mean }\end{array}$ & Min-Max \\
\hline $7-9$ & 6 & 1.66 & $0-5$ & 25 & 3.24 & $0-19$ & 8 & 1.5 & $0-5$ \\
$10-12$ & 21 & 0.42 & $0-5$ & 51 & 0.25 & $0-6$ & 16 & 1.62 & $0-15$ \\
$13-14$ & 14 & 0 & $0-0$ & 56 & 0 & $0-0$ & 4 & 1.25 & $0-5$ \\
$15-16$ & 13 & 0 & $0-0$ & 61 & 0 & $0-0$ & - & - & - \\
$17-22$ & 10 & 0 & $0-0$ & 36 & 0.11 & $0-4$ & - & - & \\
\hline
\end{tabular}

Table 3

Mean number of decayed surfaces in the permanent dentition according to handicap and age group

\begin{tabular}{|c|c|c|c|c|c|c|c|c|c|}
\hline $\begin{array}{l}\text { Age } \\
\text { (years) }\end{array}$ & No. & $\begin{array}{l}\text { Blind } \\
\text { Mean }\end{array}$ & Min-Max & No. & $\begin{array}{l}\text { Deaf } \\
\text { Mean }\end{array}$ & Min-Max & No. & $\begin{array}{c}\text { Retarded } \\
\text { Mean }\end{array}$ & Min-Max \\
\hline $7-9$ & 6 & 0 & $0-0$ & 25 & 1.12 & $0-28$ & 8 & 0.25 & $0-9$ \\
\hline $10-12$ & 21 & 0.04 & $0-1$ & 51 & 0.52 & $0-13$ & 16 & 1.25 & $0-5$ \\
\hline $13-14$ & 14 & 0 & $0-0$ & 56 & 1.01 & $0-19$ & 4 & 0.75 & $0-2$ \\
\hline $15-16$ & 13 & 0.15 & $0-2$ & 61 & 1.4 & $0-10$ & - & - & \\
\hline $17-22$ & 10 & 1 & $0-5$ & 36 & 1.75 & $0-20$ & - & - & \\
\hline
\end{tabular}

About $73.5 \%$ of the studied group had bleeding of the gums; among whom the blind showed the highest mean bleeding index ranging from 0.47 to 0.66 (Table 4). All age groups, except the $10-12$ year old group, scored $>0.50$. There were statistically significant differences in mean bleeding scores between the blind and the deaf especially in the younger and the older age groups, that is, seven to nine years $\left(X^{2}=19.33\right.$, df $\left.1, p<0.0001\right)$ and $15-16$ years $\left(X^{2}=62.3, \mathrm{df}=1, \mathrm{p}<0.0001\right)$.

About $82.8 \%$ of the subjects had calculus, with level of calculus accumulation ranging from 0.16 to 0.83 . There was no age group that had no calculus. Overall, there was an increase in mean calculus scores with age (Table 5). When the calculus scores were compared among the different handicap categories there was a significant difference between deaf and blind in the age group 15 - 16 years $(\mathrm{p}=0.008)$.
Table 4

Mean bleeding index according to handicap and age group

\begin{tabular}{lclcccc}
\hline $\begin{array}{l}\text { Age } \\
\text { (years) }\end{array}$ & $\begin{array}{c}\text { Blind } \\
\text { No. Bleeding }\end{array}$ & $\begin{array}{c}\text { Deaf } \\
\text { No. Bleeding }\end{array}$ & $\begin{array}{c}\text { Retarded } \\
\text { No. Bleeding }\end{array}$ \\
\hline $7-9$ & 6 & 0.55 & 25 & 0.13 & 8 & 0.45 \\
$10-12$ & 21 & 0.47 & 51 & 0.23 & 16 & 0.37 \\
$13-14$ & 14 & 0.55 & 56 & 0.29 & 4 & 0.29 \\
$15-16$ & 13 & 0.63 & 61 & 0.36 & - & - \\
$17-22$ & 10 & 0.66 & 36 & 0.46 & - & - \\
\hline
\end{tabular}

7-9 years $\left(\mathrm{x}^{2}=19.33, \mathrm{dfl}, \mathrm{p}<0.0001\right)$ and $15-16$ years $\left(\mathrm{x}^{2}=62.3, \mathrm{df}=1, \mathrm{p}<0.0001\right)$ 
Table 5

Mean calculus scores according to handicap and age group

\begin{tabular}{lcccccc}
\hline $\begin{array}{l}\text { Age } \\
\text { (years) }\end{array}$ & \multicolumn{2}{c}{$\begin{array}{c}\text { Blind } \\
\text { No. Calculus }\end{array}$} & $\begin{array}{c}\text { Deaf } \\
\text { No. Calculus }\end{array}$ & \multicolumn{2}{c}{$\begin{array}{c}\text { Retarded } \\
\text { No. Calculus }\end{array}$} \\
\hline $7-9$ & 6 & 0.38 & 25 & 0.16 & 8 & 0.45 \\
$10-12$ & 21 & 0.41 & 51 & 0.32 & 16 & 0.5 \\
$13-14$ & 14 & 0.6 & 56 & 0.41 & 4 & 0.29 \\
$15-16$ & 13 & 0.78 & 61 & 0.53 & & \\
$17-22$ & 10 & 0.83 & 36 & 0.66 & & \\
\hline
\end{tabular}

The inter-examiner reliability for caries was $86.6 \%$ and for calculus it was $66.2 \%$. The intra-examiner reliability for caries varied from 78.8 to $99.0 \%$, and for calculus it varied from 55.7 to $76.6 \%$.

\section{DISCUSSION}

To our knowledge, this is the first study in Tanzania that has determined the oral health status and treatment requirements of handicapped primary school pupils with hearing and / or visual disability, mental retardation or a combination of these. Thus, the findings of this study provide baseline information about the prevalence of dental caries and periodontal conditions in this special population group in Dar es Salaam. In the present study, the mean decayed deciduous surfaces (DS) for children aged seven to nine years, the deciduous surfaces scores ranged from 1.5 to 3.24 , with the deaf having twice the amount of decayed surfaces as compared with the blind and the mentally retarded. Strict comparison with normal children is difficult given the fact that there are no recent oral health studies among normal children in Dar es Salaam, with most studies having been conducted between 1986 and 1997 (13-17) and the fact that some of these studies did not investigate periodontal conditions. When compared to normal children, where mean deciduous surfaces scores have been reported by Normark and Mosha (13) to be 1.1, the amount of dental caries in the deciduous dentition of the deaf is significantly different, but not for the blind and mentally retarded children.

The DS scores of the studied group ranged from 0 to 1.75 , being highest among deaf pupils aged 17 to 22 years. In all age groups, except for the 10-12 years age group, the DS scores of the deaf were higher than that of the blind and the mentally retarded. The blind had the lowest mean DS score of between 0 and 1.0, while in the mentally retarded group the mean DS score ranged from 0.25 to 1.25 (Table 3). Compared to normal children, however, the mean decay scores are a bit higher (14-17). It is important to note the absence of any filled teeth while there is existence of considerable amount of decayed teeth signifying lack of intervention of conservativenature. The only form of intervention seems to be extractions, done on emergency basis to relieve pain.

The mean bleeding index among the blind was higher for all the age groups, followed by the mentally retarded, who had scores comparable with those of the deaf (Table 4) and accordingly, the highest mean calculus scores were found among the blind pupils than that of the other two groups (Table 5). Generally the bleeding and calculus scores of these pupils were higher than that reported in normal subjects of comparable age. In this study only $26.5 \%$ had neither bleeding gums nor calculus, while in a study conducted among normal children of comparable age from a neighbouring region showed that $75 \%$ of the pupils had no calculus or gingivitis (17).

Regarding treatment needs, 23\% required dental fillings, mainly of one and two surface restorations and more than $82 \%$ of the pupils needed scaling and polishing. The latter finding indicates a strong need for oral hygiene measures, supporting earlier findings reported by Kahabuka and Ndalanha (18). The projected dental treatment needs highlights the type of dental services required by the handicapped pupils. Effective and sustainable oral health interventional measures would require strong co-operation between families, schools, communities, regulators and legislators in order to develop and implement comprehensive oral health promotion programmes. Prevention must be aimed at reducing the greater risk of mainly periodontal diseases (bleeding and calculus). Effective early intervention strategies should include; promotion of over-all general health, obviation of stereotypes, education by dental personnel, instruction and demonstration combined with systematic evaluation, use of a fluoride containing dentifrice, and regular professional support and use of chlorhexidine rinses for those who are handicapped but can follow instructions.

In view of the findings of this study we do recommend frequent maintenance visits and oral hygiene interventions, including prophylaxis, restorative care and evaluation of the oral tissues for these handicapped pupils. There is a need of developing and implementing educational programmes for dental students, residents and practising dentists and empowering teachers and parents to become more effective managers of these pupil's oral-dental needs.

Finally, the findings of this study underscore the need for local research on feasible oral disease control programmes for the handicapped pupils and determination of parent/guardian and children predictors that are likely to influence utilisation of oral health services. 
In conclussion the amount of dental caries was not alarming in this group of disabled primary school pupils, but gingival bleeding and calculus were very common. The differences in oral health status among the handicapped indicate the existence of different needs, requiring comprehensive oral health programmes tailored to suit the different handicap groups.

\section{ACKNOWLEDGEMENTS}

To the pupils of the two primary schools for willingly participating in this study. We also wish to thank their teachers, parents and guardians for their valuable co-operation and support. Finally, we would like to thank the Muhimbili University of Health and Allied Sciences (MUHAS) for granting ethical clearance and the Dar es Salaam City Health authorities and the City Medical Officer for granting permission to conduct the study. This study was financially supported by University of Aarhus, Denmark (Grant no. 95006940).

\section{REFERENCES}

1. Shaw, L., Maclaurin, E.T. and Foster, T.D. Dental study of handicapped children attending special schools in Birmingham, UK. Commu. Dent. Oral. Epidem. 1986; 14: 24-27.

2. Forsberg, H., Quick-Nilsson, I., Gustavson, K.H. and Jagell, S. Dental health and dental care in severely mentally retarded children. Swed. Dent. J. 1985; 9: 15-28.

3. Schwarz, E. and Vigild, M. Provision of dental services for handicapped children in Denmark. Commu. Dent. Health. 1987; 4: 35-42.

4. Pope, J.E. and Curzon, M.E. The dental status of cerebral palsied children. Pediatr. Dent. 1991, 13: 156-162.

5. Nielsen, L.A. Caries among children with cerebral palsy: relation to $\mathrm{CP}$-diagnosis, mental and motor handicap. ASDC J. Dent. Child. 1990; 57: 267-273.
6. Nunn, J.H. and Murray, J.J. Dental health of handicapped children: results of a questionnaire to parents. Commu. Dent. Health. 1990; 7: 23-32.

7. Schultz, S.T., Shenkin, J.D. and Horowitz, A.M. Parental perceptions of unmet dental need and cost barriers to care for developmentally disabled children. Pediatr. Dent. 2001; 23: 321-325.

8. Adiwoso, A.S. and Pilot, T. Results of oral hygiene and hygiene education in an institution for multiple handicapped children in Indonesia. Int. Dent. J. 1999; 49: 82-89.

9. World Health Organization. Oral health surveys, basic methods. 4th ed. Geneva: World Health Organization; 1997.

10. Lauritsen, J.M., Bruus, M. and Myatt, M. EpiData. Odense, Denmark: The EpiData Association; 2002.

11. StataCorp. 2003. Stata Statistical Software: Release 8.0. College Station, TX: Stata Corporation; 2003.

12. MedCalc. Mariakerke, Belgium: MedCalc Software; 1997.

13. Normark, S. and Mosha, H. Relationship between habits and dental health among rural Tanzanian children. Commu. Dent. Oral. Epidem. 1989; 17: 317-321.

14. Frencken, J., Manji, F. and Mosha, H. Dental caries prevalence amongst 12 year old urban children in East Africa. Commu. Dent. Oral. Epidem. 1986; 14: 94-98.

15. Kerosou, E., Kerosou, H., Kallio, P. and Nyandindi, U. Oral health status among teenage school children in Dar es salaam, Tanzania. Commu. Dent. Oral. Epidem. 1986; 14: 338-340.

16. van Palenstein Helderman, W.H., Munck, L., Mushendwa, S., van't Hof, M.A. and Mrema, F.G. Effect of an evaluation of an oral health programme in primary schools in Tanzania. Commu. Dent. Oral. Epidem. 1997; 25: 296-300.

17. Kikwilu, E.N. and Mandari, G.J. Dental caries and periodontal conditions among primary school children in Morogoro municipality. East. Afr. Med. J. 2001; 78: 152-156.

18. Kahabuka, F.K. and Ndalanha, M. Parental oral health care of mentally retarded children in Ilala municipality, Dar es salaam, Tanzania. Int. J. Dent. Hyg. 2006; 4: 145-149. 